\title{
Las otras Soulaliyates: tierra y movilizaciones legítimas e ilegítimas en Marruecos \\ The Other Soulaliyates: Land and (il-)Legitimate Women's Mobilization in Morocco
}

\section{Ángeles RAMÍREZ}

Dpto. Antropología social. UAM

Angeles.ramirez@uam.es

Recibido 28/11/2017. Revisado y aprobado para publicación 17/12/2017

Para citar este artículo: Ángeles Ramírez (2017), "Las otras Soulaliyates: tierra y movilizaciones legítimas e ilegítimas en Marruecos" en Revista de Estudios Internacionales Mediterráneos, 23, 15-28.

Para acceder a este artículo: https://doi.org/10.15366/reim2017.23.002

\section{Resumen}

El artículo analiza la historia de la movilización por el derecho a la tierra, que llevaron a cabo mujeres marroquíes de diferentes regiones de Marruecos desde mediados de la década del 2000 y que continúa hasta 2017. En particular, se analizan dos casos de la misma región de Marruecos, cuyas circunstancias y desarrollo son profundamente diferentes, con desenlaces también diversos. Los dos tienen lugar en el centro de dos problemas fundamentales: las dificultades de acceso a la tierra por parte de las mujeres en el mundo y el imparable proceso de desposesión de las poblaciones rurales de sus recursos, especialmente la tierra, en los nuevos contextos neoliberales.

Palabras Clave: Movilizaciones/tierras comunales/Marruecos/mujeres

\begin{abstract}
This article addresses the issue of mobilization for the right to land, pursued by Moroccan women from different regions of Morocco since the mid-2000s and which continues in 2017. Two particular cases from the same region, whose circumstances, developments and results are profoundly different, are analysed. Both cases have two fundamental problems at their core: land access difficulties affecting women in general and the unstoppable process of resource dispossession in the rural world, especially regarding the land, in the new neoliberal context.
\end{abstract}

Key words: Mobilizations/ Collective Land/Maghreb/Women 
Este artículo trata sobre las movilizaciones femeninas ligadas al derecho a la tierra en Marruecos, especialmente las que protagonizaron las mujeres desde 2008 hasta 2017 en la franja atlántica que va desde Kenitra a Salé, en concreto, en las comunas de Haddada y Sidi Bouknadel ${ }^{1}$. En estos dos casos se plantean tres cuestiones teóricas fundamentales. La primera es el acaparamiento de tierras que se produce en buena parte del mundo, pero especialmente, en África, como parte del proceso de acumulación neoliberal y la consecuente desposesión de la población rural; la segunda, el difícil acceso a la tierra, ya sea como propietarias o como usufructuarias en el caso de las tierras colectivas ${ }^{2}$, que tienen las mujeres. La tercera tiene que ver con el papel de las movilizaciones femeninas en la reivindicación de estos derechos en contextos neoliberales.

\section{Acaparamiento de la tierra y relación de las mujeres con la tierra en el mundo}

El acaparamiento de tierras por parte de diferentes actores y la desposesión de la población rural de sus medios de vida, está teorizado al menos de desde Marx, que se refiere a ello en el capítulo XXIV del tomo I de El Capital. Las expropiaciones de tierras y la expulsión de éstas del campesinado son la base de la acumulación primitiva desde más o menos el siglo XV. Los comunales tienen un papel fundamental en este proceso que describe Marx. Se elaboran normas jurídicas a partir del siglo XVIII que dan cobertura legal a los cercamientos de tierras y consecuentes expropiaciones. La gran masa de campesinas y campesinos a los que se les escamotea su derecho a la tierra, tendrá aún que hacer frente a legislaciones que persiguen de modo sangriento a esta población que el capital considera indisciplinada y no integrada. Las leyes contra el vagabundeo y la pobreza se cebarán en este campesinado errante que ha perdido sus medios de vida y no tiene de qué subsistir. Y que como Marx dice, estos campesinos se veían castigados por algo de que lo que fueron víctimas, reducidos a mendigos y población errante ${ }^{3}$. Retomando el tema de la acumulación y evitando, como recogen Laval y Dardot (2015) poner en la misma línea todos los bienes comunes, David Harvey sostiene que la desposesión es un modo particular de acumulación y establece una analogía entre los procesos de privatización del neoliberalismo y los cercamientos de los comunes de los que hablaba Marx (Harvey, 2005). Además de nuevos mecanismos de acumulación por desposesión, como la propiedad intelectual, los servicios comunes, el agua o las semillas, sigue existiendo la desposesión de la tierra. La desposesión es permanente a lo largo de la historia de la acumulación (Harvey, 2005). La privatización de los bienes comunes es una política básica en el neoliberalismo, que el Estado ha apoyado fuertemente. Para Composto y Ouviña (2009), a esto se suma la depredación de la naturaleza, que pasa a ser un mero recurso que hay que explotar. El caso de la expropiación de tierras comunales convoca también este proceso. Los actores pueden ser diversos, como describen Cotula et al. (2009) y naturalmente, presentar variaciones según los contextos regionales. Sin embargo, en todos está presente de un modo u otro el

\footnotetext{
${ }^{1}$ La investigación está basada en una serie de recorridos etnográficos y entrevistas, que llevé a cabo de modo extensivo desde enero a junio de 2015 , con pequeñas visitas hasta 2016. Las estancias tuvieron lugar durante mi sabático en el Centre Jacques Berque de Rabat, de septiembre de 2014 a julio de 2015. Para la estancia se contó con el con el apoyo de una beca Salvador de Madariaga 2014-2015 y se llevó a cabo dentro del proyecto PARTICIPACIÓN POLÍTICA, ISLAM Y TRANSNACIONALIDAD EN EL MUNDO ARABO-ISLAMICO (CS02014-52998--c3-1-p), dirigido por Ana Planet y por la autora de este artículo. Asímismo, se colaboró en el ámbito del Proyecto HAR2012-34053. " Revueltas populares del Mediterraneo a Asia Central: Genealogia histórica, fracturas de poder y factores identitarios ", coordinado por Laura Feliu, a partir de entrevistas a activistas. Las entrevistas se han realizado en francés y la comunicación con las gentes del duar, en árabe marroquí.

${ }^{2}$ En este artículo uso indistintamente el término de (tierras) colectivas o comunales. En castellano, el segundo se usó como sustantivo y no como adjetivo, para nombrar las tierras cuya propiedad y/o usufructo correspondía a un municipio o comunidad (Arguedas, 1987; Giménez, 1991)

${ }^{3}$ Para Federici (2010), esta errancia afectó de manera especial a las mujeres. Se origina entonces la base ideológica para la caza de brujas, que sirvió como método de disciplinamiento para que las mujeres asumieran el papel de reproductoras no pagadas, que era lo más eficiente para la acumulación.
}

16 
Estado, bien como artífice directo, por medio de diferentes agencias gubernamentales, o modificando las leyes o apoyando a las empresas multinacionales; es el Estado "facilitador" del que habla Harvey en la obra citada.

La mayor parte de los acaparamientos contemporáneos se ha producido en África, relacionada con las crisis alimentarias, medioambientales, financieras o energéticas y para responder a usos de infraestructura, urbanísticos o turísticos, según relata Ruiz en un trabajo reciente (Ruiz, 2017). El mismo autor añade que los acaparamientos mayores no son necesariamente los más violentos, ya que buena parte de estos tienen lugar a partir de expulsiones de pequeñas parcelas. Los gobiernos terminan aliándose con las empresas en contra de la población rural y esta complicidad se refuerza con un discurso institucional que conecta la baja productividad al estatuto de la propiedad o el usufructo (comunal) de la tierra. Todo el proceso se acompaña de una ideología sobre la falta de productividad de los comunales, que es algo bastante habitual cuando se habla de los comunales; el propio Bouderbala (1985) apunta que las tierras colectivas no solo constituían una suerte de desafío al control del Estado, sino que eran un impedimento para el desarrollo, puesto que la inseguridad de los derechos sobre la tierra actuaba de modo disuasorio para la inversión, un discurso que hoy se hace valer aún en diversas partes del mundo como argumentario institucional para la expropiación, de modo que sea más fácil convertir un comunal que es básico para la reproducción de una comunidad en una mercancía capitalista, preparada para la agroindustria o la urbanización.

En el acceso a la tierra se observa, como otros campos, una importante brecha de género. La información de la FAO (2016) muestra cómo a pesar de que en muchos casos, está documentada la dedicación de las mujeres a la agricultura, el volumen de propietarias es menor que el de los hombres. En el caso de las tierras comunales, lo habitual en buena parte del mundo actualmente es que las mujeres no accedan a la tierra sino como dependientes de unidades domésticas encabezadas por el padre o el marido, sin que se las reconozca los derechos de ser comunitarias o ejidatarias, como ocurre en América Latina (Korol, 2016). Las especificidades de la propiedad o el usufructo de la tierra en el mundo van así configurando también nuevos modos de desposesión y de respuesta. Esto es lo que se va a tratar de analizar a continuación para el caso de Marruecos.

\section{Desde lo local: el funcionamiento de las tierras comunales en Marruecos}

Bouderbala (1985) comienza un artículo ya clásico preguntándose sobre quién legisla sobre la tierra en Marruecos, si es Dios, la yemáa ${ }^{4}$ o el Estado nacional. Lo cierto es que parte de la pregunta es hoy válida. En Marruecos, hoy, un régimen complicado de tenencia de la tierra, sumado a la adopción -y ausencia- de nuevos procedimientos de inmatriculación, ha conducido a la apropiación de tierras por parte de autoridades locales, particulares o el propio Estado.

Marruecos tiene aproximadamente 15 millones de hectáreas de tierras colectivas ${ }^{5}$, propiedad de la tribu o de las colectividades étnicas, que es así indistintamente como se nombra ${ }^{6}$. Estas tierras se gestionan según el orf o el derecho consuetudinario, que excluye a las mujeres del usufructo, incluso contraviniendo la Charia, cuya aplicación causaría grandes trastornos al campesinado, presionando sobre el patrimonio campesino, según afirma Bouderbala (1987). Los comunales se rigen por un Dahir de 1919 ${ }^{7}$, en el que el Estado colonial francés, establece las colectividades como propietarias de la tierra y la tutela del Estado

\footnotetext{
${ }^{4}$ En este caso, conjunto de adultos con capacidad de decisión en una comunidad o un pueblo.

${ }^{5}$ Según los datos de la Direction d'Affaire Rurales (www.terrescollectives.ma)

${ }^{6}$ En francés se llaman tierras de las colectividades étnicas o de la tribu, mientras que en árabe son ard yumua.

${ }^{7}$ Dahir (26 rejeb 1337) organisant la tutelle administrative des collectivités indigènes et réglementant la gestión et

I'aliénation des biens collectifs (B.O. 28 avril 1919)
} 
sobre ellas ${ }^{8}$. Se establece también su inalienabilidad, salvo si se trata del Estado, que podrá expropiar. Y finalmente, determina el derecho de los cabezas de familia, miembros de la tribu, a su usufructo. Aunque la categoría de cabezas de familia no excluyera a las mujeres, de hecho sí lo hace, como se explicará más abajo.

La tierra y sus regímenes de tenencia, como ha sucedido en otros lugares, se han adaptado desde la colonización a las exigencias capitalistas. Si durante el colonialismo, estos modos de tenencia se adaptaron para dar cabida a las explotaciones capitalistas (Bouderbala, 1987), en la etapa del neoliberalismo, las necesidades apuntan a la liberación de tierras para convertirlas en bienes inmobiliarios. Esto permite que en Marruecos se pueda hablar de una tipología de la expropiación, que se ha traducido en movilizaciones y situaciones diferentes y en la que las mujeres han estado presentes también de formas diversas. En todo momento, el Estado ha sido un actor fundamental.

Aunque puede haber variaciones en el funcionamiento de la gestión de los comunales según las peculiaridades locales, he intentado reconstruir la lógica general ${ }^{9}$ a partir de informaciones recogidas durante el trabajo de campo. Lo que se va a explicar a continuación intenta captar con fidelidad la dinámica del común.

El responsable de la gestión de los comunales es el naib, nawab en plural, que es literalmente el delegado (del ministerio) para tal fin; no tiene salario y no suele ser elegido por la yemá, sino nombrado por el caid o por el wali $^{10}$, con un mandato de seis años renovable una sola vez. A las tierras comunales tienen derecho los soulaliyín ${ }^{11}$, los descendientes masculinos de la tribu. A la pregunta de quién es miembro, quién es soulali, la gente de los pueblos (en adelante también aduar) contesta con una enorme asertividad: quien pertenece a la tribu; cuando se insiste sobre cuántas generaciones tiene que haber para que la persona en cuestión pertenezca a la colectividad y por tanto, tenga derecho a las tierras, no hay dudas. No depende de que la familia lleve un número de generaciones asentada en el territorio, sino de que sea reconocible e identificada por el resto como "los que tienen derecho", les "ayant droit" en el francés de una de las líderes de las Soulaliyates ${ }^{12}$. Los soulaliyín pueden ser gentes que hace generaciones que no residen en el douar ${ }^{13}$. En suma, la pertenencia a la colectividad queda sujeta al reconocimiento del resto, pero sobre todo, al del naib y a su consecuencia natural: que el soulali esté incluido en el listado de los ayant droit, las populares listas de distribución de las tierras. Ésta se solía revisar cada pocos años, en que los lotes se volvía a repartir en función de las necesidades familiares. Sin embargo, en muchos lugares, para evitar el excesivo desmembramiento, se decidió desde los años 70 no volver a distribuir las tierras. Si en aquel momento, había en el douar 200 familias, con acceso a 200 lotes de tierras, se queda así hasta el día de hoy. Los ancianos iban muriendo y su lote de tierra ya no se redistribuía entre todos los miembros de la tribu, sino que eran los propios herederos los que iban aprovechando la tierra de sus mayores. Este sistema también suponía que las nuevas familias que se formaron después de que se parara la distribución de las tierras, ya no tenían derecho a ella, algo que es percibido como injusto por muchas de nuestras colaboradoras. Citando a A. Daoudi ${ }^{14}$, Berriane (2015) habla de la concurrencia de un régimen de privatización, en el que

\footnotetext{
${ }^{8}$ Para Bouderbala (1996), este punto es fundamental, porque instituye el poder del Estado sobre las tribus.

${ }^{9}$ Básicamente la información viene de una de las familias de Ouled Sbita (comuna de Sidi Bouknadel) y de una responsable del funcionamiento comunal de Haddada (provincia de Kenitra).

${ }^{10}$ No hay que olvidar que tanto el caíd como el wali como el pachá, que son gobernadores provinciales o comarcales, son cargos de designación directa del Ministerio del Interior, manteniéndose al margen de las elecciones comunales 0 legislativas.

${ }^{11}$ Soulaliyín es el plural; soulali, el singular masculino y soulaliya/soulaliyates, el femenino singular y plural. Vienen de soulala, que sería algo así como línea de filiación. He mantenido la grafía francesa, aunque no corresponda a la pronunciación en castellano.

${ }^{12}$ He optado por escribir soulaliyates con minúscula cuando me refiero a las mujeres de la tribu y con mayúscula cuando me refiero al movimiento de las Soulaliyates para el reclamo de tierras.

${ }^{13}$ De hecho, es el caso de muchas familias que residen en el extranjero o en otros lugares de Marruecos y que tienen los medios y recursos para reclamar ese derecho, como pude comprobar en conversaciones en otras comunas.

${ }^{14}$ Daoudi Ahmed, 2002, "Approche théorique sur les terres collectives au Maroc ", in F. Aqil et M. Boudouah (dir.), Les structures foncières et le développement au Maroc. Cas du Gharb, Faculté des lettres et des sciences humaines de Kénitra, p. 11-14 
las tierras quedarían bloqueadas a causa de este sistema. Esto supone, tal y como explicaban las gentes de los pueblos que en realidad, ya no serían gestionadas como tierras colectivas, sino como patrimonios familiares, puesto que una vez hecho el último reparto, ningún soulali tiene ya derecho a entrar en él y son las familias las que van heredando el usufructo. Lo cierto es que todo este sistema y complicados acuerdos de distribución de tierras van a explicar buena parte de los conflictos y reclamaciones cuando suceden las expropiaciones.

En lo que respecta a las mujeres, éstas nunca han tenido derecho por sí mismas al usufructo de las tierras colectivas dentro de su propia tribu, si no es como hijas con un padre soulali vivo o esposas de un soulali vivo, es decir, como personas vinculadas con un cabeza de familia. Sin embargo, hay variaciones entre las diferentes colectividades. Berriane (2015) describe varias de estas modalidades, en las que también la edad puede ser un criterio en el reparto o en las que las mujeres pueden recibir algo en la redistribución.

Si pensamos que las tierras comunales, de bosque, cereal o pasto, han sido un apoyo importante para muchas familias campesinas, se entenderá que los conflictos hayan formado parte del paisaje rural durante décadas. Pero si se piensa en el cambio que ha supuesto la conversión de la tierra comunal desde un apoyo para el autoconsumo a una mercancía que interesa al Estado o a una inmobiliaria, será fácil hacerse una idea de los enormes conflictos y transformaciones que ha sufrido la situación social en las zonas rurales, sobre todo las cercanas a los grandes centros urbanos, así como las resistencias que eso ha provocado en la población rural. Cuando Korol (2016) se refiere a los problemas que provoca el restringido acceso a la tierra por parte de las mujeres en América Latina, destaca dos problemas: uno es la excesiva dependencia de las mujeres con respecto a los hombres que provoca esta situación; el otro es la falta de reconocimiento de los derechos a la tierra comunal en los proceso de privatización por los procesos neoliberales de comercialización de la agricultura. En otros casos, como el de Marruecos, no se trata de agroindustria, sino de urbanización. El proceso y sus resistencias es lo que se va a tratar de analizar a continuación.

\section{Reclamando los bienes comunes: las protestas en Marruecos desde 2007}

En un listado rápido de las movilizaciones en Marruecos deberían ser incluidas las producidas contra la precarización del transporte urbano (Rabat, 2009), contra la subida de la electricidad (Alcázarquivir, 2013), contra la polución de las minas (Imider, 2011) o contra las expropiaciones por obras públicas, pero quizás una de las más interesantes y sostenidas ha sido la movilización por el derecho a la tierra y a la vivienda en medio de fuertes procesos de urbanización. Las periferias intermedias de las ciudades han sido colonizadas por las elites urbanas, que en Marruecos no han gentrificado el centro (Coslado, McGuinnes y Miller, 2013), como sí ha ocurrido en las urbes europeas. Las grandes inmobiliarias, constructoras y bancos han identificado un gran negocio, estimulado por las nuevas demandas de grandes espacios verdes, deportivos y urbanizaciones. Para satisfacer este gran emprendimiento, son necesarias enormes extensiones de tierra urbanizable, transformándose así las zonas rurales en espacios residenciales en un corto espacio de tiempo. El Estado, directa o indirectamente, está siendo un actor central en el proceso.

Marruecos entró en el mapa de la protesta urbana de la mano de las llamadas primaveras árabes en 2011, con el movimiento $20 \mathrm{~F}^{15}$. Miles de jóvenes ocuparon las plazas de las grandes ciudades, convocados a través de las redes sociales y con el estímulo de diferentes grupos políticos. Sus reivindicaciones apuntaban a profundas reformas en el régimen político y a la exigencia de derechos civiles, en tanto que lo social solo ocupaba un lugar secundario. A los pocos meses, fueron prohibidas las manifestaciones convocadas en los barrios de la periferia, porque estaban arrastrando a otros sectores de la población tradicionalmente excluidos de la acción política y que sí planteaban fuertes exigencias sociales. En los años que siguieron al

\footnotetext{
${ }^{15}$ Para obtener una reconstrucción del movimiento 20F en Marruecos, ver: Hernando de Larramendi y Azaola (2011); Hibou (2011); Desrues (2012); Parejo y Feliu (2014); Feliu e Izquierdo (2016)
} 
2011, el 20F fue desactivado por diferentes motivos: por la represión policial, por el miedo generalizado a un baño de sangre y por la retirada de los islamistas, que constituían una fuerza importante en el movimiento ${ }^{16}$. Además, se aprobó una nueva Constitución que recogía alguna de las reivindicaciones del movimiento. Entre los sectores populares, el 20F supuso - tan solo al inicio- la pérdida parcial del miedo a salir a la calle a manifestarse, tal y como admitían las entrevistas con todos los activistas. Por un tiempo, las y los marroquíes tuvieron la impresión de que se podía gritar y exigir derechos. Las más mediáticas estaban vinculadas a los derechos civiles y tenían lugar en los centros urbanos, pero en el campo se producen una serie de movilizaciones vinculadas a la tierra o a la lucha contra el extractivismo. Incluso podría decirse que las movilizaciones urbanas en Marruecos no solo han de buscarse dentro de las urbes, sino fuera de éstas y contra la ciudad potencial, es decir, en la oposición a los proyectos urbanísticos, algunos de gran alcance, que desde hace una década absorben los alrededores de las grandes ciudades. La resistencia a las expropiaciones o cesiones, como se las llama eufemísticamente, así como la exigencia de derechos en las indemnizaciones, son las causas que explican la presencia de las mujeres en las protestas rurales.

En Marruecos, al filo de la tercera década del siglo XXI, se están produciendo luchas por la tierra por diferentes causas; en muchos de estos casos, hay tímidas resistencias que acaban con la expulsión. En un contexto como el marroquí, es difícil que se organicen movilizaciones sostenidas en el ámbito rural, por falta de apoyos o por miedo. Los nombres de los territorios desalojados van asociados a lujosos nuevos nichos para el turismo o a proyectos urbanísticos, que es la razón fundamental del desalojo. A unos 12 kilómetros de Agadir, se ha producido la expropiación de más de 600 hectáreas en los alrededores de Taghazout, para dotar de instalaciones a una zona que ofrece un enorme potencial turístico (Desse, 2010). Aunque el proceso comenzó a principios de la década del 2000, no ha sido culminado hasta 2015, con la expulsión de las últimas familias ${ }^{17}$. De capital saudí, la operación ha sido llevada a cabo por una de las empresas públicas creadas desde el Ministerio de Turismo. El problema de la no inscripción o matriculación de la mayoría de las tierras, ha hecho que las familias expulsadas, muchas de ellas propietarias legítimas de la tierra, no hayan podido reclamar contra la expropiación y hayan terminado por marcharse. Otro caso es el pueblo de Ouled Dlim ${ }^{18}$, en la provincia de Skhirate-Témara, en los límites de Hay Riad, uno de los barrios más lujosos y selectos de Rabat. Esta población se asienta en un terreno llamado de propiedad Guich ${ }^{19}$. El crecimiento de Hay Riad presionó de un modo insoportable al puñado de familias que seguían resistiendo en Ouled Dlim. La población, indemnizada con cantidades que considera insuficiente, se niega a abandonar las ruinas de sus casas, aun cuando ya no pueden quedarse legalmente, lo que ha provocado una dura represión ${ }^{20}$. La antigua población del área ha pasado en unos meses de ser campesina a vivir en chabolas levantadas precariamente sobre lo que fue su tierra de labor y las familias luchan por el derecho a seguir viviendo en su tierra una vez que las órdenes de expulsión han sido llevadas a cabo. En muchos casos, las empresas que expropian juegan con el estatuto difuso de las tierras y con la situación de que, de hecho, haya nuevos asentamientos sobre tierras que ya han sido expropiadas ${ }^{21}$. En el caso de Ouled Dlim, las mujeres han estado en primera línea tanto en las concentraciones como en los medios de comunicación. Para las activistas y académicas que han seguido el caso, la razón por la que las mujeres han asumido una protesta que no iba dirigida específicamente a los derechos de las mujeres, es por la idea de que la represión policial sería más suave si ésta se dirigía hacia las mujeres que si era contra los hombres. La protesta ha podido ser sostenida por el apoyo de pequeños grupos de activistas de izquierda, que han asesorado y ayudado a la población en su enfrentamiento con los poderes públicos.

\footnotetext{
${ }^{16}$ Éste es el discurso de buena parte de los activistas del $20 \mathrm{~F}$ que fueron entrevistados.

${ }^{17}$ https://www.yabiladi.com/articles/details/34062/maroc-apres-residence-familles-expulsees.html

${ }^{18}$ Sobre este caso, ver el trabajo de Soraya El Kahlaoui en

https://shameforummaroc.wordpress.com/2014/12/18/the-demolition-of-douar-ouled-dlim-in-rabat/\#more-555

${ }^{19}$ Las tierras Guich (el término procede del árabe Yaich, que significa ejército) son un tipo de propiedad específica en Marruecos; son tierras que el califa donaba a ciertas tribus aliadas, desde hace siglos, y que funcionan de hecho como tierras colectivas, pero son propiedad del Estado. Las mujeres, puesto que no son militares, no pueden en términos generales gozar del usufructo de las tierras en general (Daoudi, 2011)

${ }^{20}$ Ver “Les habitants de Douar Ouled Dlim menacés d'expulsion”, Libération 17-XII-2014.

${ }^{21}$ maghress.com/fr/lopinion/55364.
} 


\section{Movilizaciones legítimas e ilegítimas: las "buenas" y las "malas" soulaliyates}

Los dos tipos de movilización que se van a analizar a continuación se han sostenido a lo largo del tiempo y han supuesto cambios en los contextos en los que se han producido, a veces de largo alcance. Las dos han implicado discursivamente, la reivindicación de los derechos de las soulaliyates. La primera ha sido una protesta finalmente bien recibida mediáticamente e incluso en buena parte de las instancias institucionales; la segunda puede caracterizarse de marginal, por la escasa atención que ha recibido en estos niveles. Por ello me refiero en el primer caso a las soulaliyates legítimas ("buenas") y en el segundo, a las ilegítimas ("malas"). El planteamiento de las reivindicaciones, así como el recorrido de la protesta, es muy diferente, aunque sus protagonistas son -podrían ser- las mismas. De hecho, las dos protestas se encuentran en un área de apenas $30 \mathrm{kms}$, a ambos lados del bosque de la Mamora. Son comunas linderas, pero una pertenece a la provincia de Kenitra, y la otra, a la de Salé. La ruralidad del área está en entredicho por el rápido crecimiento de Salé y de Kenitra, así como por el comienzo de la explotación turística tanto de la enorme playa de las Naciones, cuanto del bosque de la Mamora. También en esta franja atlántica, el problema de las tierras comunales ha sido la amenaza de lo que Arguedas (1987) llamó quiñonización, es decir, parcelamiento y privatización de tierras comunales, proceso que se ha recrudecido con las expropiaciones por motivos urbanísticos.

\section{Movilizaciones legítimas}

En el caso marroquí, la exigencia de derechos sobre la tierra de las mujeres rurales ha convocado una conformación inédita de una revuelta social. Rkia Bellot, una de las líderes del movimiento de las Soulaliyates, me relataba en una entrevista en 2015 el calvario de las mujeres de las colectividades rurales que no tenían acceso a la tierra y en caso de reveses de la fortuna, quedaban en situación de absoluta pobreza, mientras sus hermanos varones accedían a sumas a veces importantes. En su caso, contaba la historia de su colectividad, Haddada, en la provincia de Kenitra, que es de la que partió toda la movilización, la de las legítimas Soulaliyates:

“Por ejemplo, en mi colectividad, el padre muere. En mi colectividad, hay higueras. Por ejemplo, aparece la hermana con un cubo para recoger higos. Y si está en buenos términos con su hermano y sobre todo, con su cuñada, deja que se vaya con su cubo lleno de higos, pero si no, le arranca... Tú solo eres una chica, mujer, no tienes derecho a eso".

Es el sufrimiento, la injusticia, la que nos ha hecho movernos. No es una toma de conciencia. Son ELLOS (enfatizando). Ellos nos han explotado, han hecho todo eso en nombre de la tradición, la costumbre, el ORF (enfatizando). Para ellos, la yemá está formado solo de hombres, para coger. Pero para trabajar, la mujer es la primera. Se ocupa de los hermanos, hace la colada, la cocina. Les ayuda con la tierra, arranca las malas hierbas, cuida el ganado. Para trabajar, está ahí, pero para darle, no es más que una mujer "no eres más que una mujer". Yo tengo todo el tiempo esa frase en mis oídos."

Durante años, la soulaliya llamó a distintas puertas, asumiendo que el orf no tenía que ser contradictorio ni con el buen sentido ni con el islam. Consultó con un abogado de la "vraie gauche" quien le dijo que los juristas no le resolverían el problema y la envió a la Association Démocratique des Femmes du Maroc (ADFM). Así, una mujer que no había tenido nunca contacto con el feminismo ni había considerado su problema en esos términos, recaló finalmente en una de las organizaciones feministas más importantes de Marruecos ${ }^{22}$ para solicitar consejo y ayuda. Allí pudo comprobar, según ella misma, cómo las cuestiones de las que se ocupaban las activistas feministas nada tenían que ver con los asuntos de las mujeres rurales.

\footnotetext{
${ }^{22}$ Sobre feminismos marroquíes hay un título clásico, de Daoud (1994). Sobre bibliografía en español, ver Khamsi (2012).
} 
En este sentido, es importante completar alguna información sobre la ADFM. Primero, que el movimiento feminista mayoritario en Marruecos, el de las asociaciones que procedían de los viejos partidos políticos, se ha concentrado básicamente en la lucha jurídica, en la formación y creación centros de escucha para las mujeres en situación de violencia, con una estrategia de negociación con las instituciones, pero no ha habido un trabajo sistemático - político- de formación de redes feministas (El Khamsi, 2012). Segundo, que en el 20F, una de las mayores olas de protestas en las últimas décadas en Marruecos, el movimiento no se implicó como tal. En diversas entrevistas y conversaciones informales, algunas feministas destacaron que el hecho de que en el 20F tuviera un lugar tan prominente los militantes islamistas fue discutido como un hándicap para su participación en el movimiento. Un militante de la $\mathrm{AMDH}^{23}$ nos contaba en una entrevista en 2014 que esa forma de movilización -la del 20F- no entraba en las manejadas habitualmente por las feministas, que estaban concentradas en la cuestión jurídica y de lucha contra las violencias machistas con otras dinámicas reivindicativas. Esto muestra muy bien el perfil político de la ADFM, que no incluye una confrontación sostenida con las instituciones ni cuestiona el sistema.

¿Por qué entonces una asociación como la ADFM, sin una trayectoria de lucha con mujeres rurales ni de conformación de redes se implica en una lucha como la de las Soulaliyates? Tanto el relato de la señora Bellot como el de la responsable en la ADFM del dossier de las Soulaliyates, muestran el interés que el asunto suscitó desde el principio en la asociación, que comenzó a elaborar toda una estrategia de apoyo a lo que aún no era un movimiento. La ADFM no se implicó como parte de este movimiento, sino que se dedicó a "empoderar" a las mujeres soulaliyates. En realidad, y como muy bien describe Berriane (2016), las Soulaliyates proporcionaban datos del terreno para el trabajo de cabildeo que hacían las feministas; ese tipo de contacto con el terreno, con las "mujeres reales" era algo relativamente novedoso en el trabajo feminista y la propia responsable de la asociación compartía su sorpresa al oir hablar por primera vez en su vida de los problemas vinculados a las tierras colectivas y la falta de derecho de las mujeres.

Las activistas de la ADFM construyeron alrededor de las Soulaliyates todo un dispositivo con varios objetivos; en primer lugar, conseguir un conocimiento ajustado de la zona y de sus especificidades; y segundo, formar a las propias mujeres en el uso de herramientas políticas que les permitieran el reclamo de sus reivindicaciones y el control mediático. La idea de la participación de las mujeres como usufructuarias legítimas de las tierras colectivas se fue extendiendo a lo largo de Marruecos hasta conformar una protesta a nivel nacional. El trabajo conjunto de las feministas y las mujeres soulaliyates llegó hasta la Comisión de la Condición Jurídica de la Mujer de Naciones Unidas, llamando la atención de la directora de ONU-MUJERES, Michele Bachelet, que acabó visitando a las Soulaliyates en $2012^{24}$. En todo este tiempo de protestas, se logró del Estado la edición de una circular ${ }^{25}$ que, sin tener rango de ley, otorgaba el acceso de las soulaliyates de la provincia de Kenitra a los beneficios derivados de las expropiaciones (llamadas cesiones en la versión francesa); habría que esperar hasta el 2012 para obtener una circular semejante que diera cobertura a todas las Soulaliyates del país y que incluyera no solo el disfrute de las indemnizaciones por expropiación, sino el derecho al usufructo de la tierra en condiciones normales ${ }^{26}$. Desde 2007 hasta al menos el 2015, la ADFM ejerció presión sobre el ministerio del interior, presentándose en las comisiones que se establecieron para tal fin e incluso abordando directamente al ministro ${ }^{27}$. No se ha conseguido que haya un cambio de ley ni que el orf se haya modificado en el sentido de igualar a hombres y mujeres en el acceso. Sin embargo, la primera gobernadora de Marruecos fue nombrada en Kenitra a principios de 2014 y en su primer 8 de marzo designó por primera vez a cinco

\footnotetext{
${ }^{23}$ Association marocaine des Droits humains, la principal asociación de referencia de lucha por los derechos humanos, integrada por militantes procedentes de la extrema izquierda y con un papel prominente en el movimiento $20 \mathrm{~F}$.

${ }^{24}$ Este dato fue puesto de manifiesto sobre todo por la responsable de la ADFM

${ }^{25}$ Circular no 51 del 14 de mayo de 2007 del Ministerio del Interior, en la que el ministro del Interior ordena al wali de la provincia de Kenitra que incluya a las mujeres de la colectividad, las soulaliyates, en la lista de los "ayant droit" a recibir indemnizaciones.

${ }^{26}$ Ver http://www.terrescollectives.ma/Pages/ar/sujets/mars\%202013/sujet-mois.cshtml. Ver también Berriane (2015)

${ }^{27}$ La responsable de la ADFM relata cómo se presentaron sin invitación en las comisiones, mencionándole al guarda el nombre de un personaje importante, o cómo abordaron directamente al ministro para hablarle del problema de la tierra y las mujeres.
} 
mujeres como naibates, es decir, administradoras de las tierras comunales de sus colectividades. Este número aumentaría tímidamente después. Una de las primeras mujeres en ser nombrada naiba fue justamente la que había sido la líder de la protesta y de quien partió la preocupación y el trabajo de autoorganizarse, la señora Bellot. Para el movimiento feminista, estos logros se deben directamente al trabajo que las mujeres Soulaliyates llevaron a cabo, junto con el propio movimiento feminista. En este caso, la ADFM, aunque organizó sit-in y acompañó a las soulaliyates en concentraciones y manifestaciones, optó por continuar en su línea y llevar a cabo un trabajo que ellas siempre llaman de plaidoyer con los poderes públicos. A diferencia del movimiento que se analizará a continuación, ni los objetivos de la protesta ni los mecanismos para conseguir los fines, desafiaban el programa neoliberal ni los intereses del Estado.

\section{Movilizaciones menos legítimas}

El segundo tipo de movilización parte de Ouled Sbita, en la comuna de Sidi Bouknadel, provincia de Salé, que es un aduar de aproximadamente unas 250-300 familias que se encuentra situado a ambos lados de la vieja carretera que une Rabat y Kenitra, a unos $15 \mathrm{kms}$ de la primera y unos 20 de la segunda. Es uno de tantos pueblos con hábitat diseminado a la orilla de la carretera, alternándose las casas con pequeñas manchas de bosquecillos de eucaliptos. Tiene sin embargo una especificidad importante: su proximidad a la playa más larga de la región, la playa de las Naciones (plage des Nations). Hasta finales de los noventa e inicio de los 2000, la playa de las Naciones, de mala fama por la potencia de sus corrientes, aunque bien considerada entre surfistas, era una enorme extensión de unos 10 kilómetros de extensión donde se levantaba un solitario hotel que estaba vacío la mayor parte del año. Las tierras que están entre la población de Ouled Sbita y la playa, son colectivas o no matriculadas. Su uso se inscribe en las formas tradicionales de explotación de la tierra explicadas más arriba.

En Ouled Sbita, según un soulali del aduar, hay dos criterios para acceder a la tierra colectiva: según el número de miembros de la familia, esto es, a más miembros, más tierras, y del tipo de familia; si en una familia extensa patrilocal, tal y como es la forma más habitual en el área, el abuelo está aún vivo, la casa recibe la porción familiar; si no vive, todos los varones de la familia tienen derecho a su propia parte. Esto significa que una familia extensa grande, formada por la pareja mayor, tres hermanos varones con sus esposas, hijas e hijos y con alguna hermana soltera, tendrá menos acceso a la tierra que si los tres núcleos familiares están separados, una vez desaparecida la pareja anciana. También supone que las mujeres de la familia nunca tienen acceso por sí mismas a la tierra, solo a partir del usufructo legítimo del marido o del padre, como sucede en la mayor parte de los aduares. Las mujeres de Ouled Sbita, aduar que dista apenas unos kilómetros de la comuna de Haddada, donde comenzó la movilización de las Soulaliyates según su propio relato, se consideran beneficiarias de las circulares que sancionaron su derecho a la tierra y que fueron resultado de las luchas, pero su problema es muy diferente y tiene que ver con la resistencia a ser desalojadas de la tierra que habitan, junto con sus familias.

En la movilización hay una soulaliya central a la que llamaré Souad V. y cuyo relato sitúa el inicio de la lucha hacia 2007. Entonces llegaron al douar unas personas que se identificaron como de Dakhilia ${ }^{28}$, del ministerio del Interior, aduciendo que necesitaban las tierras para el Rey. Las gentes del douar accedieron sin plantear ningún problema, convencidas de que seguirían con su vida y de que, en todo caso, "el rey nunca iba a permitir que nos quedáramos en la calle"; las familias recibieron unos 50 dirhams por metro cuadrado. Los representantes del ministerio, siempre por medio del naib, compraron 351 Has -de la carretera hasta la playa, dicen siempre las gentes de Ouled Sbita-. Sin embargo, al poco tiempo, algunas familias comenzaron a recibir el documento de expulsión de la tierra y entonces advirtieron que habían sido expropiadas no solo de las tierras comunales que usaban para el ganado o para coger arena y vender,

\footnotetext{
${ }^{28}$ Nombre con el que se conoce al ministerio del Interior en árabe.
} 
sino del territorio que ocupaban sus propias casas. Al mismo tiempo, los terrenos que ellos vendieron a 50 dirhams el metro a la $\mathrm{CDG}^{29}$, comenzaron a ser revendidos a 10.000 dirhams, mientras su entorno más inmediato se cubría de excavadoras y buldóceres y allá donde había una senda entre huertos, ahora se levantaba una calle con bordillos y hormigón, franqueada por farolas. La empresa que compró los terrenos de Ouled Sbita al Estado es Addoha ${ }^{30}$, que construyó una oficina a pocos metros de sus casas, sede administrativa y ahora es el punto de partida de las concentraciones de las activistas.

Después de descubrir que habían sido engañadas, las familias, encabezadas por mujeres, comenzaron a buscar abogados, de modo que obligaran a la empresa primero, a medir correctamente los terrenos que estaban expropiando -unas 391 hectáreas que hasta la fecha la empresa se ha negado a medir de nuevo- y segundo, a indemnizar a las familias para que en caso de que verdaderamente tuvieran que marcharse, pudieran contar con algo de dinero para comenzar. Pensaban que la obligatoriedad por parte del Estado de indemnizar también a las mujeres -y no solo a los hombres- de las colectividades, que fue un logro del movimiento de las Soulaliyates, les permitiría aumentar a las familias el magro monto recibido a cambio de sus tierras. En este punto es cuando el sistema de expropiaciones de los comunales, privatizando los bienes comunes para hacer negocios y contando con la complicidad y el estímulo del Estado, se encuentra con la gestión tradicional de las tierras colectivas. Las familias del pueblo se dirigieron a su naib y descubrieron que había estado aprovechándose también de las tierras colectivas, añadiendo o quitando nombres a la lista de los ayant droit y por tanto, de los potenciales receptores de indemnizaciones.

Las mujeres de Ouled Sbita, encabezadas por una campesina de menos de 30 años, casada con un asalariado y madre de dos hijos, comenzaron a recorrer diferentes asociaciones y abogados hasta que finalmente, la Ligue Marocaine pour la Citoyenneté et les Droits de l'Homme (LMCDH), de origen sindical, se interesó por el caso. La asociación, ubicada primero en Rabat y luego en Kenitra, se ocupaba de apoyarles jurídicamente y de ofrecerles también un espacio de discusión e información. Además, el responsable de la asociación era la persona que organizaba a las mujeres para llevar a cabo concentraciones en los dos puntos fundamentales: enfrente del Parlamento, en Rabat y al lado de la oficina de Addoha, como se mencionó más arriba. Aunque las mujeres son quienes organizan las concentraciones y quienes actúan de portavoces, también acuden los hombres a ellas. Normalmente, estos se mantienen en un segundo plano, bien separados y con su propia pancarta o bien detrás de las mujeres. Desde el inicio de las movilizaciones se ha mantenido el carácter femenino de la protesta, imitando el de las soulaliyates originales, las que reclamaban el derecho a la tierra. Tiene mucha fuerza la idea de que la policía, en caso de conflicto, no cargará contra un grupo de mujeres campesinas, siendo que además, hay alguna muy anciana; además, la cabeza visible de la protesta tiene como estrategia fortalecer una asociación que acaba de crear, llamada las Soulaliyates de Ouled Sbita.

La mayoría de las familias ya habían recibido en el verano de 2015 el expediente de expulsión y el objetivo de la movilización en abril de 2017 seguía siendo aumentar el monto de las indemnizaciones y evitar la expulsión. Las mujeres, en mayo de 2017, siguen saliendo a hacer concentraciones a la carretera y muy ocasionalmente, a Rabat, a veces con los hombres. Las relaciones con la asociación son difíciles: ésta es acusada por las soualiyates de pedir dinero por ayudar a las mujeres, por medio de la afiliación, aunque siguen colaborando. Las concentraciones, que reúnen a unas decenas de hombres y mujeres, se producen cuando hay alguna visita de periodistas u otros activistas. Entretanto, Souad, que es hija de una familia relativamente bien situada en el aduar ${ }^{31}$, se presentó a las elecciones comunales de septiembre de 2015 como independiente y salió elegida, con lo que ahora es representante de la comuna ${ }^{32}$. Actualmente, está siendo requerida por los diferentes partidos políticos presentes en el territorio, que buscan aprovechar su capital social y político para ganar implantación en la zona y ella piensa que podría ser eventualmente útil;

\footnotetext{
${ }^{29}$ La Caisse de Depot et Gestion de Marruecos es una empresa financiera pública, que gestiona las finanzas y los fondos en relación al territorio, el turismo o el sector inmobiliario del Estado.

${ }^{30}$ Addoha es el mayor grupo inmobiliario marroquí y su presidente, Sefrioui, el tercer hombre más rico de Marruecos. Está participado en un 50\% por el Estado marroquí.

${ }^{31}$ Berriane (2016) se refiere también a la situación relativamente acomodada de la familia de otras líderes Soulaliyates como un dato importante.

${ }^{32}$ Comuna (rural o urbana) es una demarcación territorial en Marruecos que corresponde a subdivisiones provinciales. 24
} 
sin embargo, según su propio relato, ella ya ha dicho que no a algunos partidos que han intentado su cooptación, porque su ambición, dice, es conseguir indemnizaciones para todos los habitantes de Ouled Sbita y evitar que tengan que abandonar su tierra. Para la movilización fue muy importante el hecho de que al inicio de 2015, el problema fuera identificado por ATTAC Maroc y este grupo lo incluyera como uno de sus puntos de trabajo activista. Sin embargo, la marginalidad de ATTAC en cuanto a medios, justamente por el tipo de causas por las que se implican, hace que su impacto sea muy pequeño comparado con el que tuvo ADFM con las soulaliyates. Las relaciones entre la LMCDH y ATTAC en esta causa no son demasiado fluidas y no hay cooperación entre ellas.

Durante la primer mitad de 2017 se denunció por corrupción a uno de las responsables ministeriales de la gestión de los comunales: Noreddin Boutayeb, secretario de Interior ${ }^{33}$, fue acusado de mala gestión y malversación de caudales públicos en el asunto de Ouled Sbita como responsable del contrato, secretario de Interior. La denuncia, que solo confirma la razón de los habitantes de Ouled Sbita, ha vuelto a caldear momentáneamente la protesta y ha hecho que se plantearan concentraciones enfrente del gobierno civil de Salé, algo inédito en esta trayectoria de concentraciones en sitios "permitidos". También ha regenerado la desesperación, en la idea de que ésta puede ser la última oportunidad de reclamar sus tierras.

En este tiempo, Souad, así como algunos soulaliyín de Ouled Sbita, se han hecho con unas cuantas herramientas mínimas que le permiten enviar informaciones y noticias por whatsapp o hacerse presentes a las activistas de modo que su causa no sea olvidada. Su caso ha saltado a las páginas de bastantes publicaciones internacionales y han sido entrevistadas por prestigiosos periódicos. En casi todos ellos, se habla de la reclamación de las mujeres para obtener los mismos derechos que los hombres, aunque se hace de un modo ambiguo y confuso. Souad usa esto como un modo de llamar la atención en diferentes contextos internacionales, con el convencimiento de que el tema de la injusticia contra las mujeres frente a los hombres, va a encontrar más fácilmente acomodo en los intereses de un público internacional y porque los propios medios van buscando ese tema, pero este tipo de artículos invisibiliza el verdadero problema ${ }^{34}$, que no es el acceso o no de las mujeres a la tierra, sino la impunidad de las expropiaciones por parte de las grandes empresas y la complicidad activa del Estado.

Entretanto, el grupo Addoha ha construido, por medio de su empresa inmobiliaria Prestigia, una enorme urbanización con un campo de golf de 18 hoyos, allá donde estaban en parte las tierras del aduar, algunos de cuyos habitantes trabajan ya en las urbanizaciones.

\section{Conclusiones}

Los proyectos urbanísticos son básicos en la reconstitución de la gobernanza en la era neoliberal, como bien apuntan Zemni y Bogaert (2011) y el papel del Estado, aliado o parte promotora de estos grandes emprendimientos, es básica también en Marruecos. Por ello, las movilizaciones de Ouled Sbita van mucho más allá de lo que representan un puñado de hombres y mujeres gritando consignas - que simultanean los abucheos contra el millonario dueño de Addoha con los vivas al Rey- en los márgenes de la antigua carretera de Kenitra. El hecho de que, como más arriba se mencionó, Addoha esté participada en su capital por el Estado, le da a las protestas un tono paradójico y ambiguo, puesto que el Estado, el verdadero artífice de las expropiaciones, es vitoreado a través de los vivas a su jefe.

Los reclamos de las Soulaliyates originales, que acabaron en Naciones Unidas o hablando ante del Foro de los Derechos Humanos, organizado en Marrakech en 2014 por el propio Estado marroquí, buscaban un

\footnotetext{
${ }^{33}$ Badil, 30 de marzo y 6 de abril de 2017.

${ }^{34}$ Ver el New York Times del 7 de mayo de 2017 (https://www.nytimes.com/2017/05/07/world/africa/moroccosulaliyyate-lands-women-inheritance.html?smid=tw-nytimes\&smtyp=cur\& $r=0$ ).
} 
cambio jurídico que les permitiera acceder a las indemnizaciones en los casos de expropiación en las mismas condiciones que los hombres de su familia. No se cuestionaban las indemnizaciones ni las políticas de expropiación porque de hecho, no se trataba de la expropiación de pueblos enteros, sino de las tierras comunales. El problema estaba planteado casi como un problema interno, mujeres frente a hombres, sin cuestionar ninguna estructura de poder que tuviera que ver con el Estado o con las elites en juego. La respuesta a las reivindicaciones llega con los cambios jurídicos que, aunque solo tengan forma de una circular, no de una ley, permiten que los reclamos de las Soulaliyates, puedan ser satisfechos por el momento en la mayoría de los casos. Incluso la respuesta de las instituciones superó el alcance de las primeras reclamaciones, que se referían solo al acceso a la tierra durante las expropiaciones, ya que la última circular reconocía el derecho en toda circunstancia. Las soulaliyates no van contra el modelo de acumulación neoliberal.

El caso de Ouled Sbita, sin embargo, es diferente. Primero, porque se trata de la expropiación del douar entero. Los reclamos de sus habitantes, entonces, cuestionan no solo la gestión local de la tierra por parte de los nuab, sino el propio papel del ministerio del Interior, que en ocasiones fuerza a los nuab a firmar la venta del terreno donde se asientan sus propias casas, como afirmaba el presidente de la LMCDH. También se enfrentan a la complicidad del Estado -la complicidad del modelo de acumulación del Estado- en los procesos de expropiación de las multinacionales, comprando la tierra por medio de agencias estatales y luego revendiendo a las multinacionales para los megaproyectos urbanísticos. Obviamente, sus reivindicaciones no tuvieron espacio en el Foro de Marrakech, ante la gran desesperación de Souad y sus vecinas, puesto que el Foro trataba de todo lo contrario ${ }^{35}$.

La diferencia entre los dos movimientos, el de las Soulaliyates y el de Ouled Sbita, explica también el tipo de apoyos que consiguieron en su lucha. En el primer caso, una organización como la ADFM, bien conectada con los financiadores europeos, consiguió todo un programa de formación, negociando en Marruecos y legitimando su propio carácter de red feminista. En el segundo, una asociación marginal, de dudosa estrategia (LMCDH) y un movimiento de extrema izquierda fuertemente reprimido en Marruecos ${ }^{36}$, ATTAC, apoyan a las gentes de Ouled Sbita. Quizás la metáfora más gráfica es que las responsables de la ADFM lograron introducirse en una comisión del ministerio del Interior para discutir de las soulaliyates ${ }^{37}$, sin ser invitadas, en tanto que los miembros de ATTAC, ya en su primera visita al douar para tratar de entender la situación y comenzar con el trabajo político, fueron acosados por teléfono in situ y perseguidos por la policía en la carretera de Kenitra ${ }^{38}$. La marginalidad de la reclamación de Ouled Sbita se reproduce en estatuto marginal de los apoyos que recibe.

El hecho de que las reivindicaciones de Ouled Sbita utilicen el lenguaje de los derechos de las mujeres, muestra la legitimidad -relativa- de algunas demandas frente a otras. Si el "enemigo" es el marido, el hermano o la autoridad masculina, no supone un problema estructural para el Estado; es más, engancha con toda una retórica salvacionista, en la que hay que rescatar a las mujeres rurales de la represiva tradición -retórica hacia adentro- o a las musulmanas de los hombres de su cultura -retórica hacia los financiadores externos; pero si el enemigo es el ministerio del Interior, las multinacionales o el Estado marroquí, el problema es bien diferente. No hay apoyo ni nacional ni internacional. Por eso las soualiyates de Ouled Sbita se siguen reclamando herederas de las primeras, porque son muy conscientes de la diferencia del reclamo y de que el primero tiene más visos de atraer el interés de posibles actores y de protegerlas de la represión policial. La compleja situación de la propiedad y el usufructo de la tierra, tanto las formas comunales o Guich, como la situación de la no matriculación de la mayor parte de las tierras en

\footnotetext{
${ }^{35}$ El boicot al Foro por parte de organizaciones de derechos humanos marroquíes y no marroquíes, acusándolo de simulacro de respeto de derechos humanos en un país muy cuestionado por los organismos internacionales en este sentido, fue noticia en muchos medios de comunicación. Ver, por ejemplo, en los medios españoles: http://www.lamarea.com/2014/11/30/las-mayores-ong-marroquies-boicotean-el-foro-mundial-de-derechoshumanos-de-marrakech/

${ }^{36}$ ATTAC Maroc es objeto de acoso y persecución constante por parte de las autoridades en Marruecos, que incluyen la vandalización de sus locales en Rabat.

${ }^{37}$ Entrevista con la responsable de ADFM (ver nota 26 de este mismo capítulo.)

${ }^{38}$ La autora de este capítulo asistió en primera persona a esta persecución y acoso. 
Marruecos, facilita tanto la arbitrariedad como la estigmatización de la población campesina en el curso de los procesos de expropiación.

Entretanto, la expulsión ligada a la expropiación suele ser el inicio de un proceso imparable de empobrecimiento y exclusión de las familias campesinas. La protesta de Ouled Sbita pone de manifiesto que las expropiaciones de pueblos enteros y su desaparición, arrojan a la gente a la miseria y a unas vidas que no merecen la pena ser vividas, porque no hay una política de realojo ni de indemnizaciones que permita a la mayoría de la gente comenzar a vivir dignamente en otro lugar. Tampoco se repite el proceso de la acumulación en determinados momentos históricos, donde estos campesinos y campesinas "liberados" podían asalariarse en la industria. Además, y en general, las movilizaciones ligadas a las expulsiones, dado que nunca afectan a más de unos cientos de personas en cada pueblo, no consiguen atrapar la atención de la opinión pública, terminando por desaparecer de las noticias y de las preocupaciones de la mayoría de la gente. Pero el recuerdo de las protestas y la resistencia de algunas de ellas, así como los conocimientos adquiridos por las asociaciones y movimientos sociales, ayuda a organizar otras nuevas. El recorrido de la protesta permitirá analizar en el futuro si las acciones conseguirán la tierra para todo el colectivo o si solo se librarán de la expulsión los pequeños grupos familiares a los que pertenecen los líderes de la movilización y el resto se verá condenado a la errancia de la que hablaba Marx en el siglo XIX.

A pesar de ser Marruecos un país que reprime fuertemente la expresión pública -y privada- de la disidencia, sobre todo cuando se trata de exigir derechos sociales, se puede decir que las movilizaciones no han hecho más que comenzar.

\section{Bibliografía}

ARGUEDAS, José María (1987): Las comunidades de España y del Perú. Madrid, Instituto de Cooperación Iberoamericana-Ministerio de Agricultura, Pesca y Alimentación.

BERRIANE, Yasmine (2015): "Inclure les « n'ayants pas droit »: Terres collectives et inégalités de genre au Maroc ", L'Année du Maghreb [En ligne], 13 | http://anneemaghreb.revues.org/2546; https://doi.org/10.4000/anneemaghreb.2546 (septiembre de 2016): "Bridging social divides: leadership and the making of an alliance for women's land-use rights in Morocco", Review of African Political Economy, Volume 43, 2016. Issue 149; African women's struggles in a gender perspective, pp. 350-364, https://doi.org/10.1080/03056244.2016.1214118

BOUDERBALA, Negib (1985): "Loi et société au Maroc : le cas des terres collectives ", Bulletin écono- mique et social du Maroc, numéro spécial Hommage à P. Pascon, Rabat, pp. 63-73.

(1987): "Loi et société au Maroc: le cas des terres collectives", Bulletin Economique et. Social du Maroc (Rabat), pp: 159-161, S. 63-73.

(1999): "Les systèmes de propriété foncière au Maghreb. Le cas du Maroc", en JOUVE A. M. y BOUDERBALA, N. (ed.): Politiques foncières et aménagement des structures agricoles dans les pays méditerranéens: à la mémoire de Pierre Coulomb, Montpellier, CIHEAM.

COMPOSTO, Claudia y OUVIÑA, Hernán (2009): “Acumulación por despojo y nuevos cercamientos: Mercantilización de los bienes comunes y antagonismos renovados en América Latina", $V$ Jornadas de Jóvenes Investigadores, Instituto de Investigaciones Gino Germani, Facultad de Ciencias Sociales, Universidad de Buenos Aires, Buenos Aires.

COSLADO, Elsa; McGUINNESS, Justin y MILLER, Catherine (Dir.) (2013): Médinas immuables? Gentrification et changement dans les villes historiques marocaines (1996-2010). Rabat, Centre Jacques Berque, https://doi.org/10.4000/books.cjb.275

COTULA, L., VERMEULEN, S., LEONARD, R. and KEELEY, J. (2009): “Land Grab or Development Opportunity? Agricultural investment and International land deals in Africa", IIED/FAO/IFAD, London/Rome. 
DAOUDI, Fatiha (2011): Droits fonciers des femmes au Maroc Entre complexité du système foncier et discrimination. Étude sur le terrain des droits fonciers des femmes au Maroc. Halshs, 00694238.

DESRUES, Thierry (2012): "Le Mouvement du 20 février et le régime marocain : contestation, révision constitutionnelle et élections ", L'Année du Maghreb, VIII | 2012 : Dossier : Un printemps arabe ? Maroc. L'année politique. https://doi.org/10.4000/anneemaghreb.1537.

DESSE, Michel (2010): "Le Maroc en mutation. Mobilités touristiques et recompositions socio-spatiales dans la région d'Agadir", Norois. Environnement, aménagement, société, 214 | 2010 https://doi.org/10.4000/norois.3127.

EL KHAMSI, Rajae (2012): Identidad y género: aproximación al discurso feminista en Marruecos, Departamento de Sociología y Antropología Social, Institut Universitari d'Estudis de la Dona, Universitat de Valencia.

FAO (2016): Gender and Land Statistics (acceso 22 de febrero de 2017) http://www.fao.org/3/a-i4862e.pdf FEDERICI, Silvia (2010) Caliban y la bruja. Mujeres, cuerpo y acumulación

originaria. Madrid: Traficantes de sueños.

FELIU MARTÍNEZ, Laura e IZQUIERDO BRICHS, Ferrán (2016): "Estructura de poder y desafíos populares. La respuesta del régimen marroquí al Movimiento 20 de Febrero", Revista de Estudios Políticos, pp. 195-223, https://doi.org/10.18042/cepc/rep.174.07

GIMÉNEZ, Carlos (1991): Valdelaguna y Coatepec: permanencia y funcionalidad del régimen comunal agrario en España y México, Madrid, Ministerio de Agricultura, Alimentación y Medio Ambiente

HARVEY, David (2005): "El "nuevo" imperialismo: acumulación por desposesión", Socialist register 2004, Clacso, 2005.

HERNANDO DE LARRAMENDI, Miguel y AZAOLA, Bárbara (septiembre de 2011): "Protestas ciudadanas y cambios en el mundo árabe", Revista de Occidente, 364, pp. 23-39.

KOROL, Claudia (2016): Somos tierra, semilla, rebeldía: Mujeres, tierra y territorios en América Latina, Fundación Intermón-Oxfam.

LAVAL, Christian y DARDOT, Pierre (2015): Común. Ensayo sobre la revolución en el siglo XXI, Barcelona, Gedisa.

PAREJO FERNÁNDEZ, María Angustias y FELIU MARTíNEZ, Laura (2014): “Nouvelles et anciennes dynamiques constitutionnelles au Maroc: les acteurs politiques face à la reforme constitutionnelle de 2011", en SEDJARI, Ali (Dir.) Pouvoir et contre-pouvoir à l'heure de la démocratie et des droits humaines au Maroc, París, L'Harmatan, pp. 319-356.

ZEMNI, Sami y BOGAERT, Koenraad (2011): "Urban renewal and social development in Morocco in an age of neoliberal government", Review of African Political Economy, 38:129, pp. 403-417, http://dx.doi.org/10.1080/03056244.2011.603180. 